\title{
Technical Manual for Automated J-R Curve Analysis Program Based on the ASTM E1820-18 Normalization Method
}

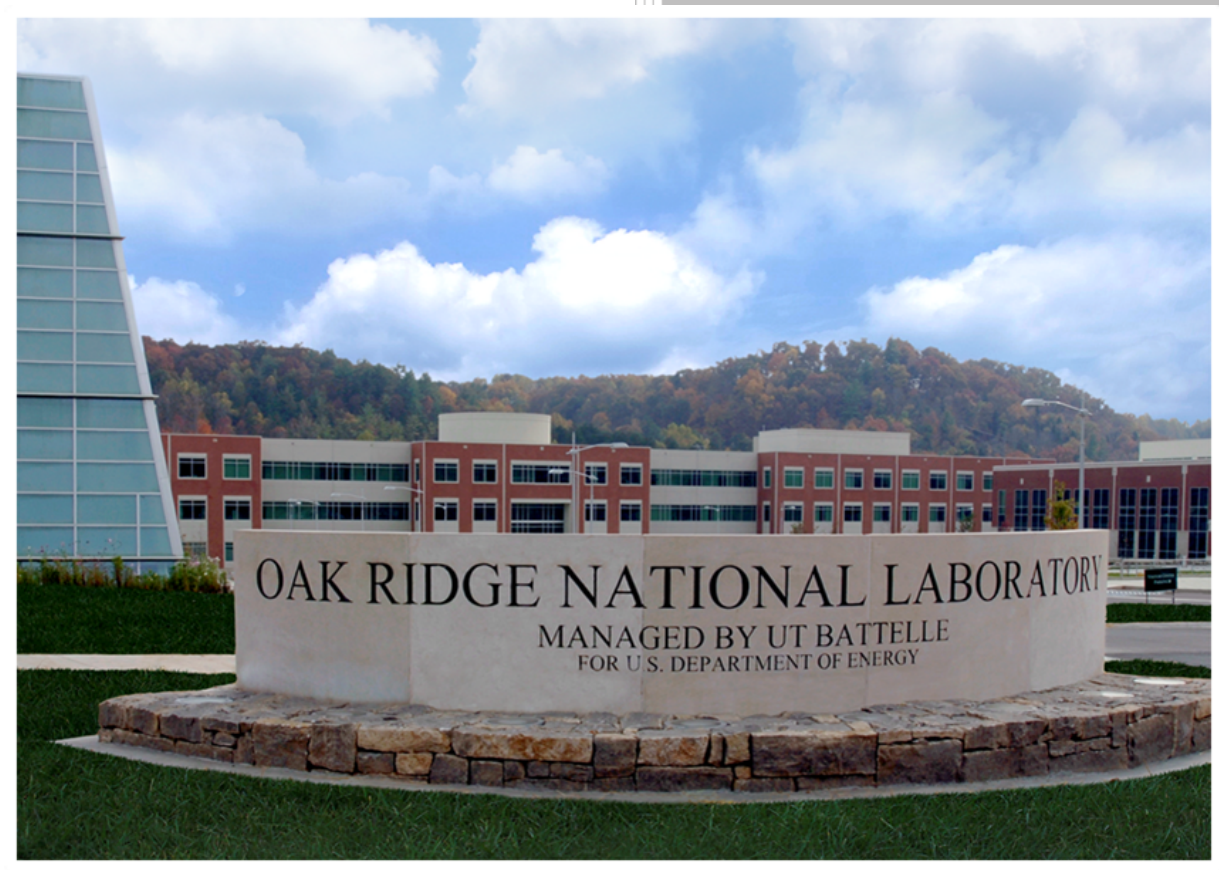

Logan Clowers ${ }^{1,2}$

Alberto Esteban Linares ${ }^{1,3}$

Xiang Chen ${ }^{4}$

${ }^{1}$ Oak Ridge Institute for Science and Education ${ }^{2}$ The University of Tennessee, Knoxville ${ }^{3}$ Vanderbilt University ${ }^{4}$ Oak Ridge National Laboratory

October 31, 2018 


\section{DOCUMENT AVAILABILITY}

Reports produced after January 1, 1996, are generally available free via US Department of Energy (DOE) SciTech Connect.

Website www.osti.gov

Reports produced before January 1, 1996, may be purchased by members of the public from the following source:

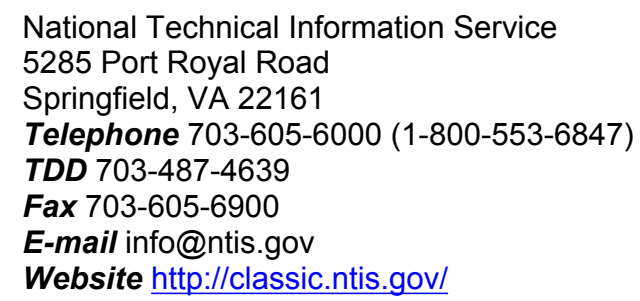

Reports are available to DOE employees, DOE contractors, Energy Technology Data Exchange representatives, and International Nuclear Information System representatives from the following source:

Office of Scientific and Technical Information

PO Box 62

Oak Ridge, TN 37831

Telephone 865-576-8401

Fax 865-576-5728

E-mail reports@osti.gov

Website http://www.osti.gov/contact.html

This report was prepared as an account of work sponsored by an agency of the United States Government. Neither the United States Government nor any agency thereof, nor any of their employees, makes any warranty, express or implied, or assumes any legal liability or responsibility for the accuracy, completeness, or usefulness of any information, apparatus, product, or process disclosed, or represents that its use would not infringe privately owned rights. Reference herein to any specific commercial product, process, or service by trade name, trademark, manufacturer, or otherwise, does not necessarily constitute or imply its endorsement, recommendation, or favoring by the United States Government or any agency thereof. The views and opinions of authors expressed herein do not necessarily state or reflect those of the United States Government or any agency thereof. 
Materials Science and Technology Division

\title{
TECHNICAL MANUAL FOR AUTOMATED J-R CURVE ANALYSIS PROGRAM BASED ON THE ASTM E1820-18 NORMALIZATION METHOD
}

\author{
Logan Clowers ${ }^{1,2}$, Alberto Esteban Linares ${ }^{1,3}$, and Xiang Chen ${ }^{4}$
}

${ }^{1}$ Oak Ridge Institute for Science and Education

${ }^{2}$ The University of Tennessee, Knoxville

${ }^{3}$ Vanderbilt University

${ }^{4}$ Oak Ridge National Laboratory

Date Published:

October 31, 2018

Prepared by

OAK RIDGE NATIONAL LABORATORY

Oak Ridge, TN 37831-6283

managed by

UT-BATTELLE, LLC

for the

US DEPARTMENT OF ENERGY

under contract DE-AC05-00OR2272 
This page intentionally left blank 


\section{TABLE OF CONTENTS}

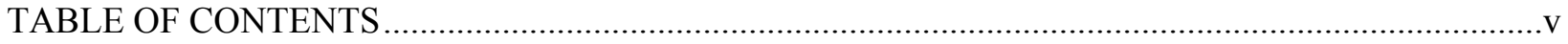

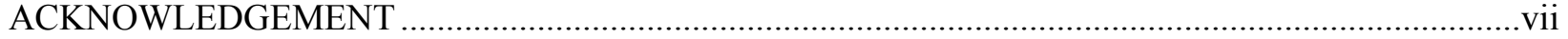

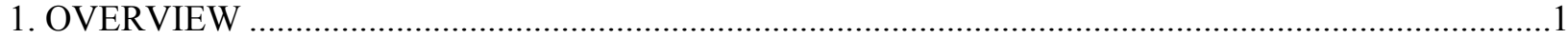

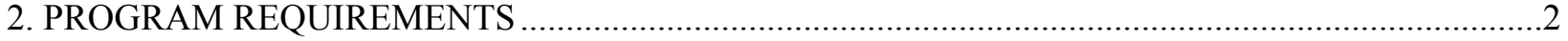

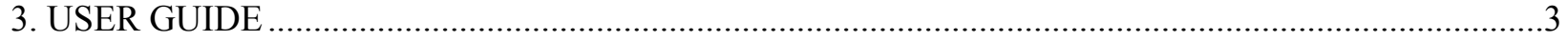

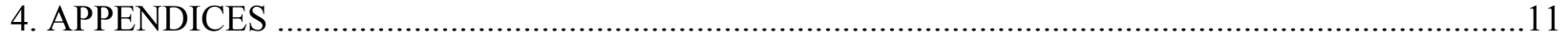

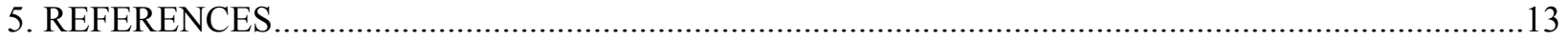


This page intentionally left blank 


\section{ACKNOWLEDGEMENT}

This research was sponsored by the U.S. Department of Energy, Office of Nuclear Energy, Light Water Reactor Sustainability Program, Materials Research Pathway, under contract DE-AC0500OR22725 with UT-Battelle, LLC/Oak Ridge National Laboratory. The authors extend their appreciation to Dr. Keith Leonard for his programmatic support. We would like to thank Dr. Mikhail Sokolov and Dr. Randy Nanstad for their technical review of this manual. We also appreciate help from Dr. Jungwon Kim in setting up the GitLab webpage for hosting the source codes, executable files, etc. for the analysis program. 
This page intentionally left blank 


\section{OVERVIEW}

The J-integral vs. crack growth resistance curve (J-R curve) is a useful tool for evaluating materials fracture toughness in the ductile region. The widely applied standard for conducting such tests is American Society for Testing Materials (ASTM) Standard E1820-18 [1], in which the normalization analysis method is described in Annex 15. The normalization method requires only load-displacement data and crack size measurements before and after testing, which greatly simplifies the fracture toughness testing and alleviates many issues that arise when testing in extreme conditions. Despite these advantages, the normalization method requires complicated analysis procedures and there is currently no publicly available open-source software to perform such analysis. To facilitate the application of this method, an automated program is seen as the best option to yield valid and replicable results. A program was developed using MATLAB $^{\circledR}$ to perform the complex data analysis procedures of the normalization method. The program was then compiled using the MATLAB Application Compiler tool for general use. The compiled software, in the form of a standalone executable program, has a user-friendly graphical interface and is readily compatible with modern Windows operating systems. The program is applicable for the four most commonly used fracture toughness specimen geometries:

1. $\mathrm{C}(\mathrm{T})$ : compact tension

2. $\mathrm{DC}(\mathrm{T})$ : disk compact tension (crack mouth opening displacement on the load line)

3. SEB(LLD): single edge bend with load line displacement measurement

4. SEB(CMOD): single edge bend with crack mouth opening displacement measurement

From the load-displacement data, crack length measurements, and material parameters, the program generates analysis parameters, adjusted crack lengths, J-R curve data, fracture toughness values, and the derived J-R curve figure. The general flow of the program can be viewed in Appendix 1. 


\section{PROGRAM REQUIREMENTS}

\subsection{System Requirements}

Operating System: $\quad$ Windows $^{\circledR} 10$ (Recommended), Windows 8.1 or Windows 7

Processor: $\quad$ Intel ${ }^{\circledR}$ or $\mathrm{AMD}^{\circledR} \mathrm{x} 86-64$ processor; $1 \mathrm{Ghz}$ or faster

Disk Space: $\quad$ 2GB of free HDD space

RAM: $\quad$ 4GB (Minimum), 8GB (Recommended)

Graphics: $\quad$ Processor Integrated Graphics (Minimum)

\subsection{Installation}

Users should run Normalization_installer.exe for the installation of the analysis program package. Once complete, users should save the program shortcut link in the same folder containing all input data files to be used. The program must then be run from this shortcut. On completion of running the program, the output data files will also be saved in this same folder. It is recommended to copy the program shortcut link into individual folders where each dataset is separately stored. This ensures that the correct files are being analyzed and there is no risk of overwriting previous data files. 


\section{USER GUIDE}

\subsection{Starting Instructions}

Upon startup of the normalization program, a pop-up window with instructions (Fig. 1) will appear giving a general guide to the user through the first few steps of the analysis, including the selection of specimen geometry, load-displacement data, and initial material and testing parameters. The user should click the "OK" button to proceed to the next step.

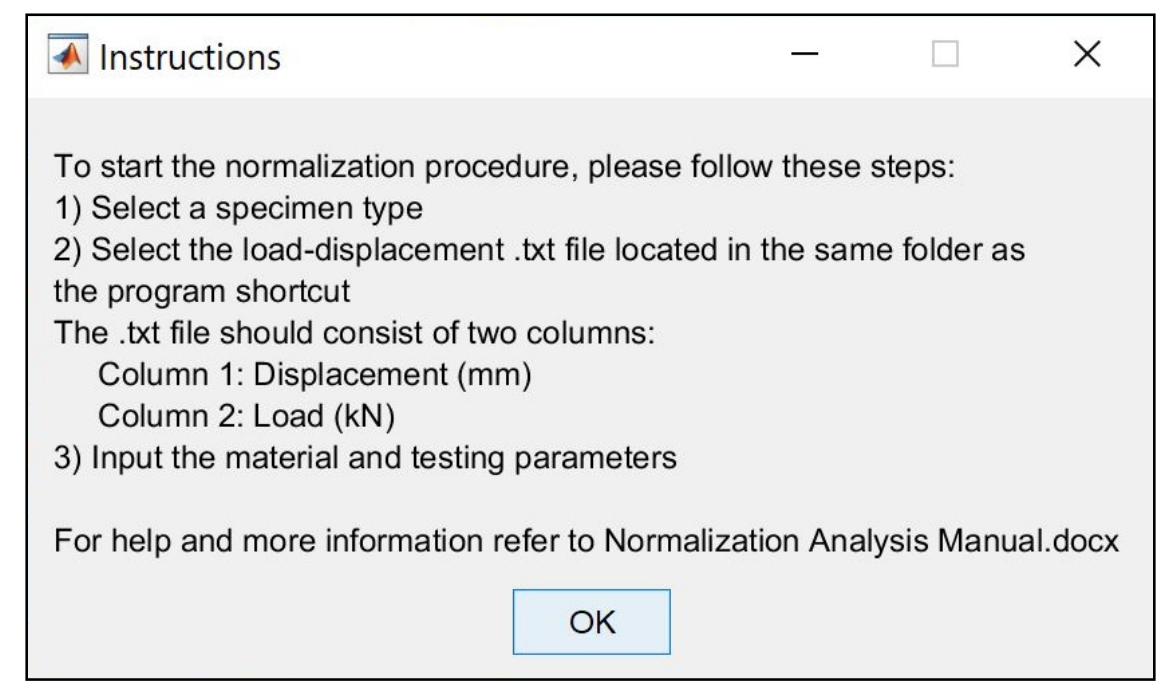

Fig. 1 Program startup pop-up window.

\subsection{Specimen Geometry and Load-Displacement Data Selection}

Following the initial instructions panel, another pop-up window (Fig. 2) will appear in which the user has to select the specimen geometry that will be analyzed. The four options for specimen geometries are $\mathrm{C}(\mathrm{T}), \mathrm{DC}(\mathrm{T}), \mathrm{SEB}(\mathrm{LLD})$, and $\mathrm{SEB}(\mathrm{CMOD})$.

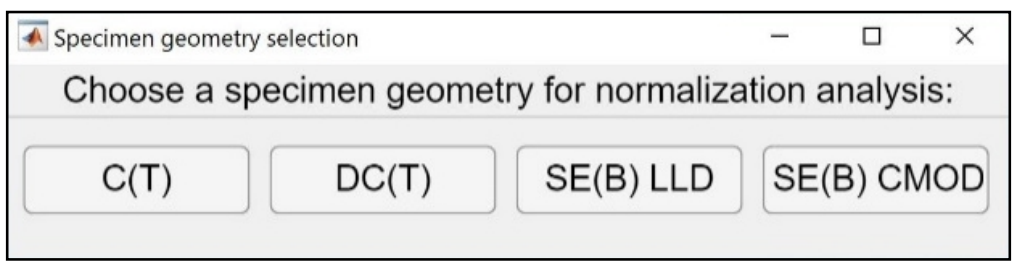

Fig. 2 Pop-up window for specimen geometry.

Afterwards, a file selection pop-up window (Fig. 3) will open the folder where the program shortcut is located and prompt the user to choose a text file for the load-displacement data to be analyzed. The file must have two columns with the first column being the displacement in units of $\mathrm{mm}$ and the second column being the load in units of $\mathrm{kN}$. 


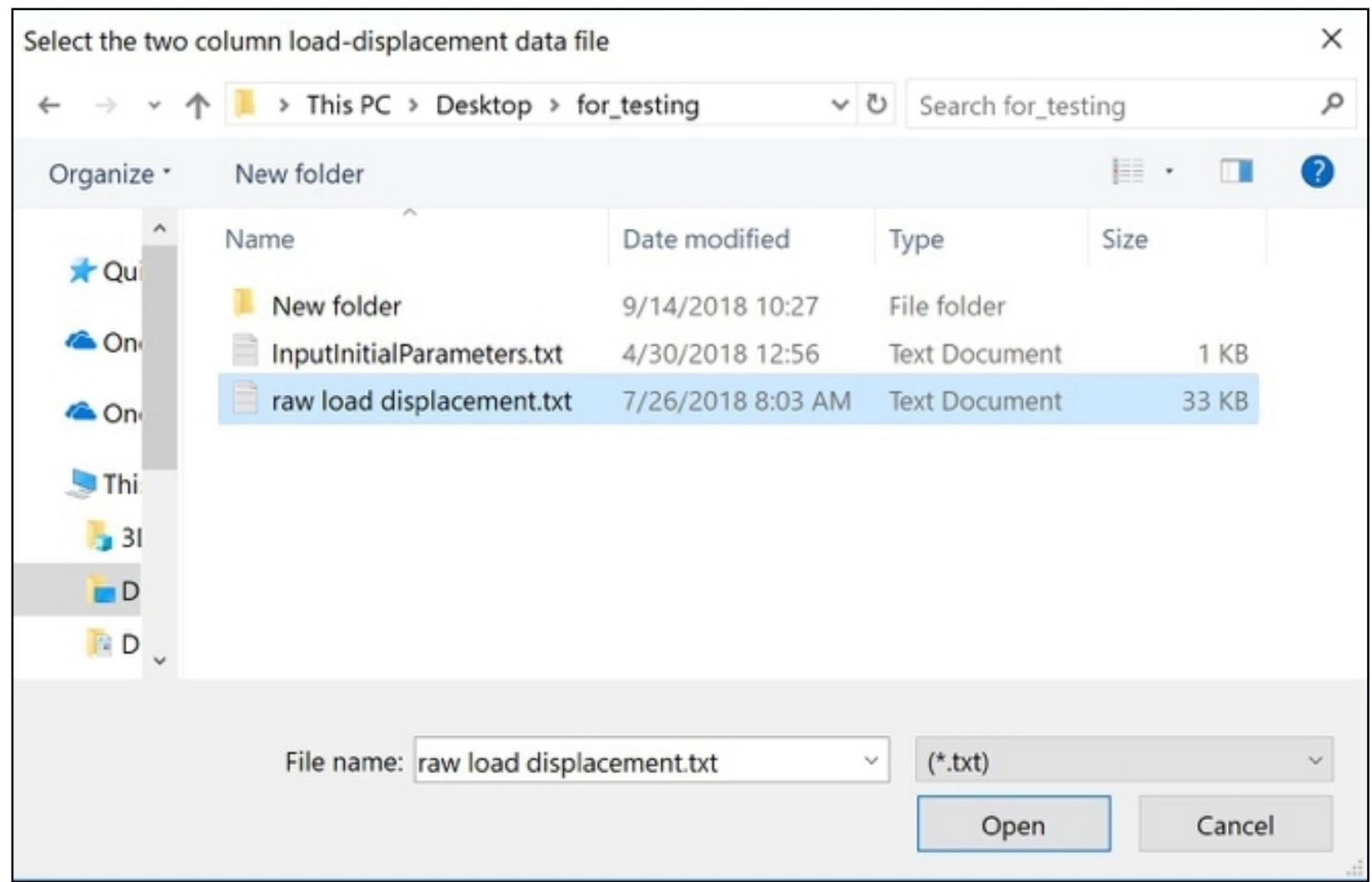

Fig. 3 Pop-up window for selecting the load-displacement data file.

\subsection{Specimen Identification}

After selecting the text file with the load-displacement data, the user is required to input the specimen ID (Fig. 4). The specimen ID will be in the file name extension of each output file. After inputting the specimen ID, the user should click the "OK" button to proceed to the next step.

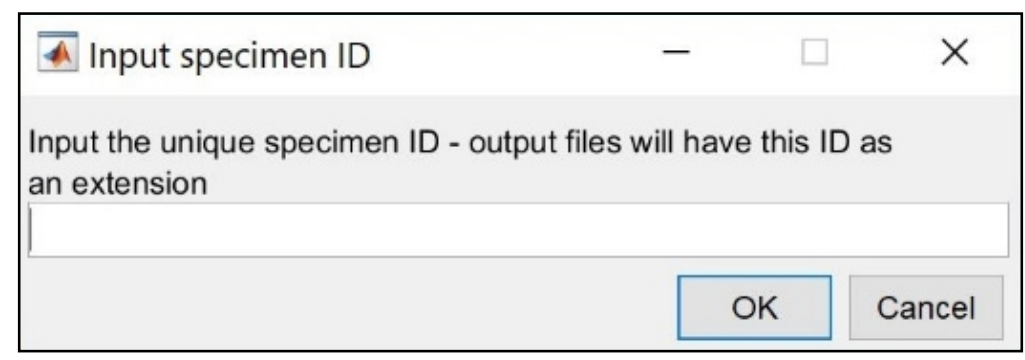

Fig. 4 Pop-up window for inputting specimen ID.

\subsection{Initial Test Parameters}

Once the specimen ID is inputted, the user will be prompted (Fig. 5) to input the initial test parameters by either manual input or selecting a text file containing the parameters. If the user chooses a text file, the file should have one column and nine rows with each row containing the numerical values of the parameters in the following order: 


XXX.XXX
XXX.XXX
XXX.XXX
XXX.XXX
XXX.XXX
XXX.XXX
XXX.XXX
XXX.XXX
XXX.XXX

Young Modulus (GPa)

Poisson's Ratio

Ultimate Tensile Stress (MPa)

Yield Stress (MPa)

Thickness (mm)

Net Thickness excluding side grooves $(\mathrm{mm})$ Width (mm)

Avg. Initial Crack Length (mm)

Avg. Final Crack Length (mm)

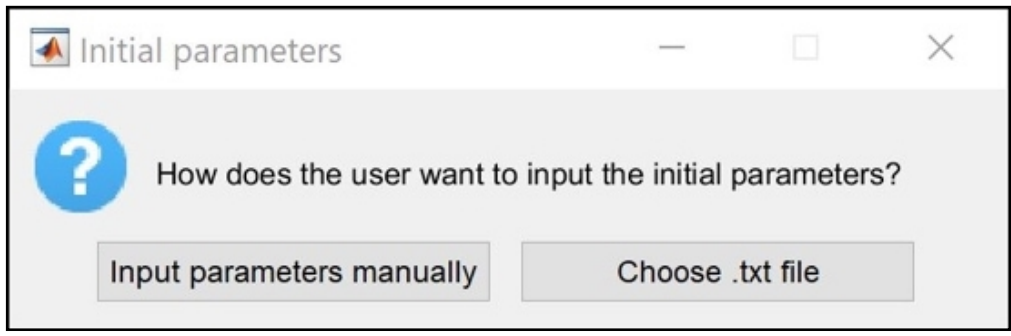

Fig. 5 Pop-up window for inputting the initial parameters.

Whether the user inputs parameters manually or chooses a text file to populate the parameters, a pop-up window (Fig. 6) for the test parameters will appear and the user can view and edit the parameters if needed. The user should click the "OK" button to proceed to the next step.

\begin{tabular}{|l|}
\hline Test parameters \\
Young's modulus (GPa): \\
280 \\
Poisson's ratio: \\
0.3 \\
Ultimate tensile strength(MPa): \\
1200 \\
Yield strength (MPa): \\
900 \\
Thickness (mm): \\
17 \\
Net thickness (mm): \\
\hline 10 \\
Width (mm) \\
\hline 20 \\
Avg. initial crack length (mm): \\
8 \\
\hline 12 \\
\hline
\end{tabular}

Fig. 6 Test parameter pop-up window. 


\subsection{Displacement Measurement Conversation (only for $\mathrm{C}(\mathrm{T})$ specimens)}

In the case of analyzing a $\mathrm{C}(\mathrm{T})$ specimen, an additional dialogue box (Fig. 7) will appear prompting the user to specify whether the displacement was measured along the load line (LL) or not. If the user chooses No, another dialogue box (Fig. 8) will appear prompting the user to enter the distance between the clip gauge (CG) and the load line in unit of $\mathrm{mm}$. The program will then automatically convert the CG displacement measurement to the load line displacement based on the following equation [2]:

$$
V_{L L}=V_{c}\left(\frac{a_{0}+r b_{0}}{a_{0}+r b_{0}+c}\right)
$$

where

$\mathrm{V}_{\mathrm{LL}}=$ load line displacement,

$\mathrm{V}_{\mathrm{c}}=$ clip gauge displacement measured at a distance $\mathrm{c}$ from the load line,

$\mathrm{a}_{0}=$ initial crack length,

$\mathrm{r}=$ constant equal to 0.33 ,

$\mathrm{b}_{0}=$ initial uncracked ligament length,

$\mathrm{c}=$ distance from the load line to the clip gauge location.

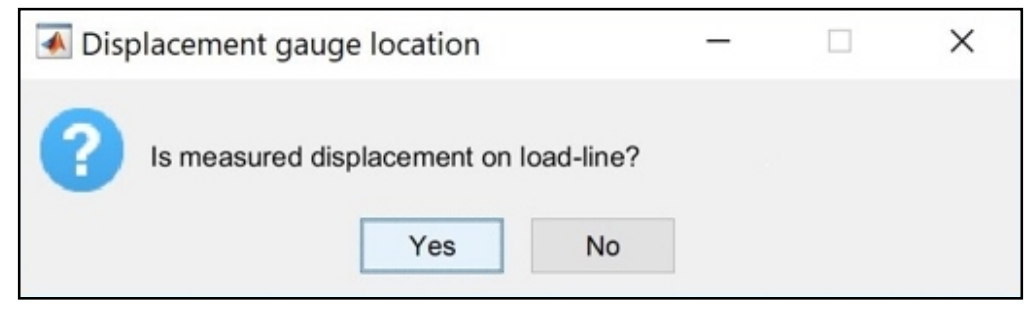

Fig. 7 Displacement gauge location window.

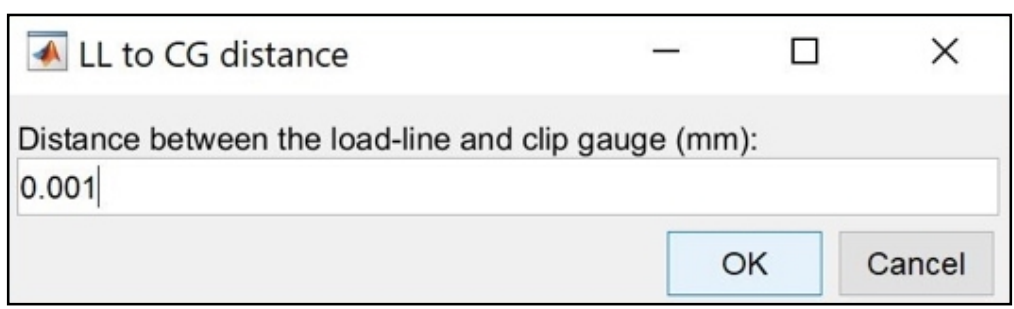

Fig. 8 Load line (LL) to clip gauge (CG) distance dialogue box.

\subsection{Normalization Curve Fitting}

In this step, the normalization program will fit the normalized load and displacement data (Fig. 9a) based on the procedures in section A15.2.7 of ASTM E1820. The program will start with the first normalized plastic displacement (first- $\mathrm{v}_{\text {plii }}$ ) of 0.001 and make an initial fitting up to, but not including the normalized maximum load. The obtained fitting parameters become the initial values for the fitting coefficients in Eq. A15.5 of ASTM E1820. Then, starting with first- $\mathrm{v}_{\text {pli' }}=0.001$, the program will automatically search for the suitable normalized load-displacement data for the fitting such that the difference between the fitted curve and the final normalized load is less than $0.5 \%$ of the final formalized load. Once the user clicks the "OK" button of the residual analysis window, another window (Fig. 9b) will appear asking whether the fitted curve is acceptable. If both the residual value and fitted curve are accepted by the user, the program will continue to the J-R curve calculation in section 3.8. Otherwise, the program will try to reperform the normalization curve fitting detailed in the next section 3.7. 

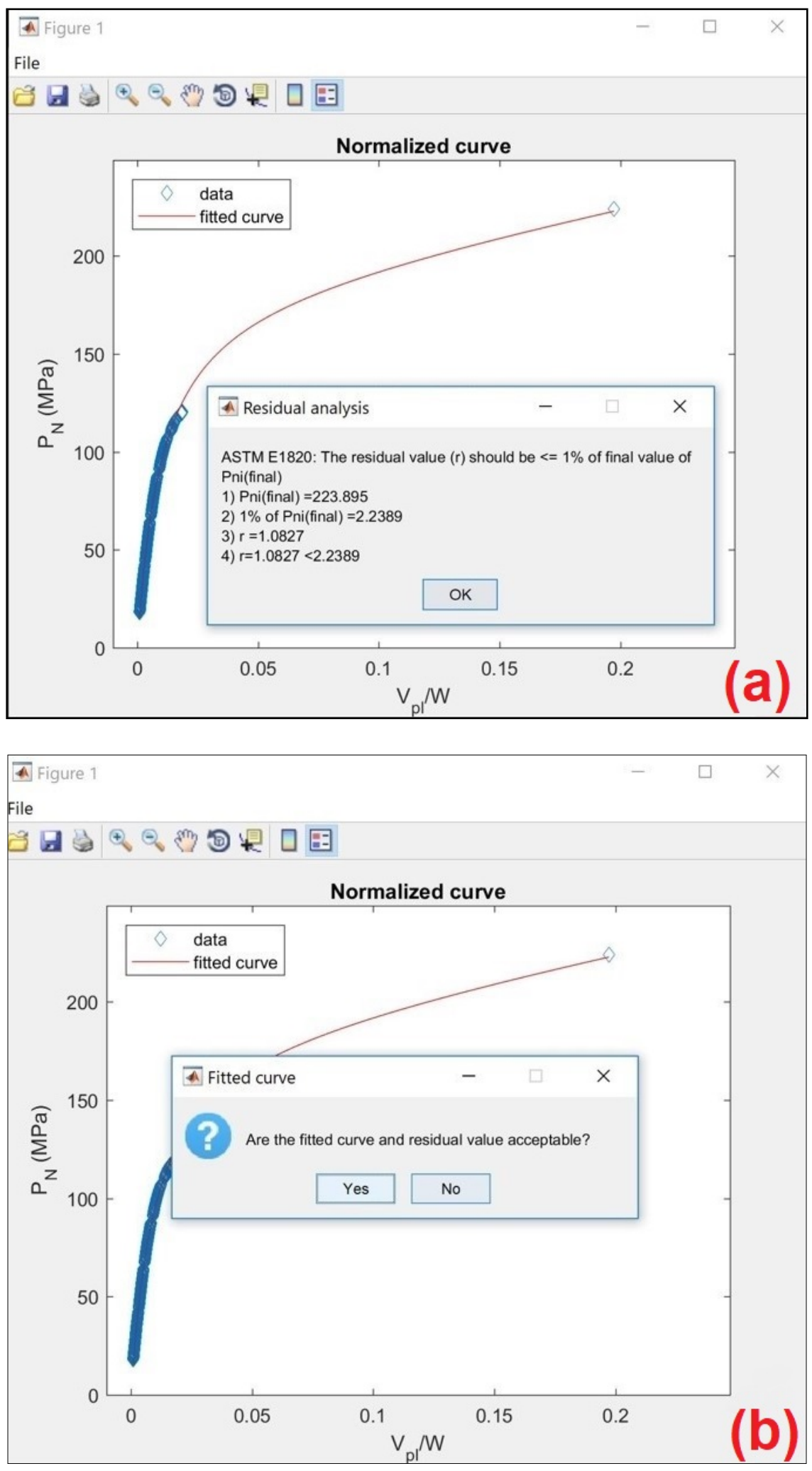

Fig. 9 Normalization curve fitting. 


\subsection{Refit the Normalization Curve}

If the user clicks the "No" button in Fig. 9b, the program will perform additional fitting to find a satisfactory solution. In detail, the program will begin by incrementing the starting- $\mathrm{v}_{\text {pli' }}$ by +0.002 each time the user clicks the "No" button in Fig. 9b. This incremented starting- $\mathrm{v}_{\text {pli }}$ is then iterated down with a step size of -0.001 until the starting- $\mathrm{v}_{\text {pli }}$, equals first $-\mathrm{v}_{\text {pli }}$, and the curve fitting parameters are also revised with each successive iteration. If no acceptable curve is found and starting- $\mathrm{v}_{\text {pli }}$ exceeds 0.006 , the program will then permanently increment the first- $\mathrm{v}_{\text {pli }}$ by +0.001 and resume the loop of incrementing on the starting $-\mathrm{v}_{\mathrm{pli}}$, until a satisfactory curve and residual value is found. Once first- $\mathrm{v}_{\text {pli }}$ exceeds 0.006 , the program will display an error box stating that normalization cannot be performed with the data set. If the curve is accepted at any point, the program will continue to calculate the adjusted crack length values and J-R curve. For more information, users are referred to the Appendix 2: Normalization Function Program Flow Chart and the source codes for the normalization analysis program

\subsection{J-R Curve Calculation}

Once the fitted normalized load displacement curve is accepted, the program will calculate the J$\mathrm{R}$ curve. First, the adjusted crack length values are calculated and then the J-R curve is derived as in Fig. 10. The same plot also includes the construction line, the exclusion lines, the offset line, and the power regression line fitting J-R curve data points between two exclusion line. In addition, a pop-up window will ask if the J-R curve is acceptable. If the user clicks on "Yes," the program will continue to section 3.9 for data qualification. If the user selects "No," the program will restart the normalization analysis with the first $-\mathrm{v}_{\text {pli }}=$ first $-\mathrm{v}_{\text {pli }},+0.001$. This loop will stop working when first- $\mathrm{v}_{\mathrm{pli}}>0.006$ without an acceptable J$\mathrm{R}$ curve. In that case, a pop-up window will let the user know that the normalization analysis cannot be performed to yield the J-R curve. For more information, users are referred to the Appendix 2: Normalization Function Program Flow Chart and the source codes for the normalization analysis program. 


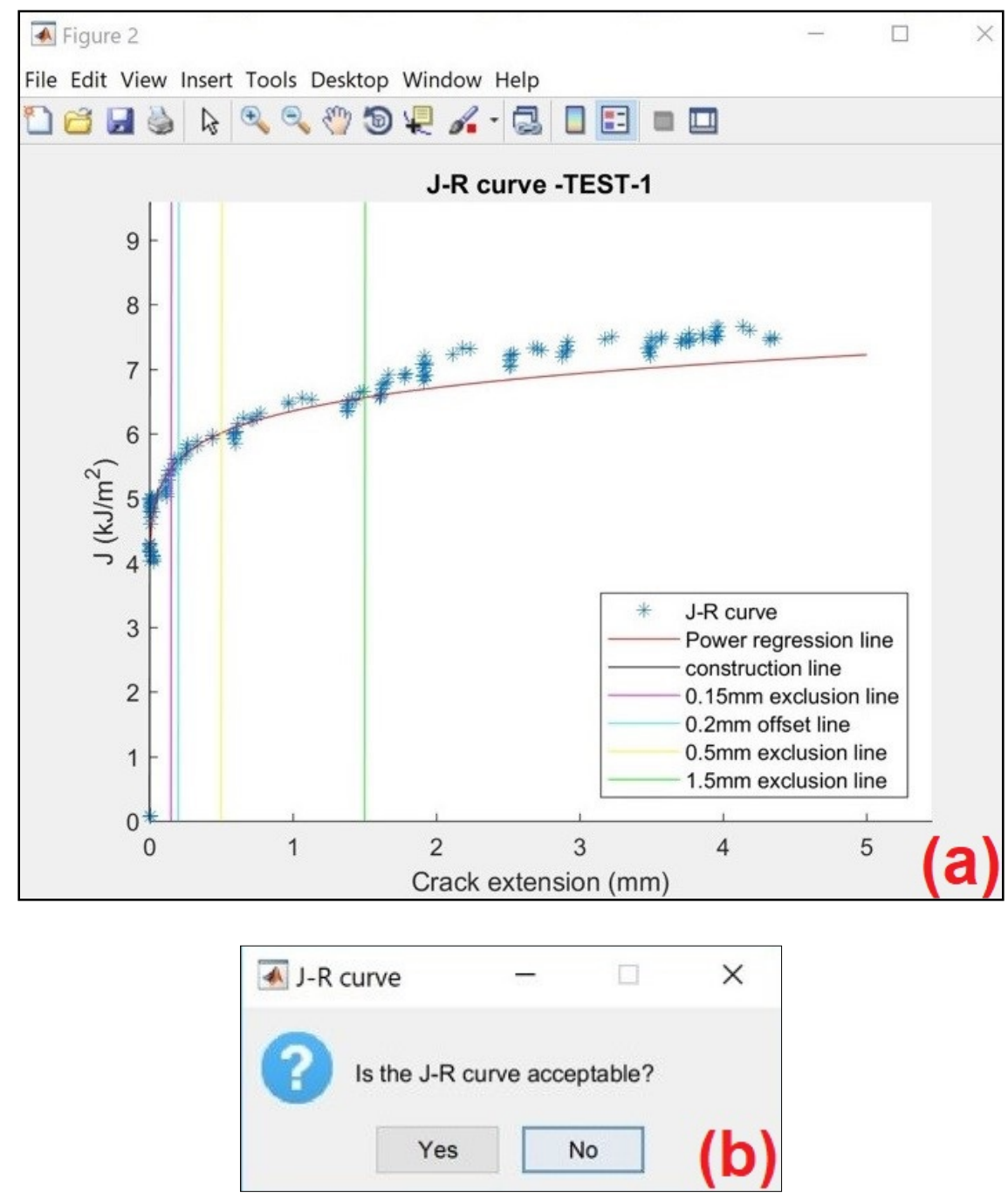

Fig. $10 \mathrm{~J}-\mathrm{R}$ curve analysis.

\subsection{Qualification of Data}

Once the J-R curve is accepted, a window box (Fig. 11) will appear showing if the power coefficient $\mathrm{C}_{2}$ defined in section A9.6.5 of ASTM E1820 meets the qualification requirement by comparing $\mathrm{C}_{2}$ value with 1.0. If $\mathrm{C}_{2} \geq 1.0$, no fracture toughness values can be determined and the program will close. If $\mathrm{C}_{2}<1.0$, after clicking the "OK" button, another window box (Fig. 12) will appear showing what additional qualifications in ASTM E1820 need to be met to qualify $\mathrm{J}_{\mathrm{Q}}$ as $\mathrm{J}_{\mathrm{IC}}$. This window box also shows the values of the $\mathrm{J}_{\mathrm{q}}, \mathrm{K}_{\mathrm{Jq}}$, and tearing modulus defined in [3].

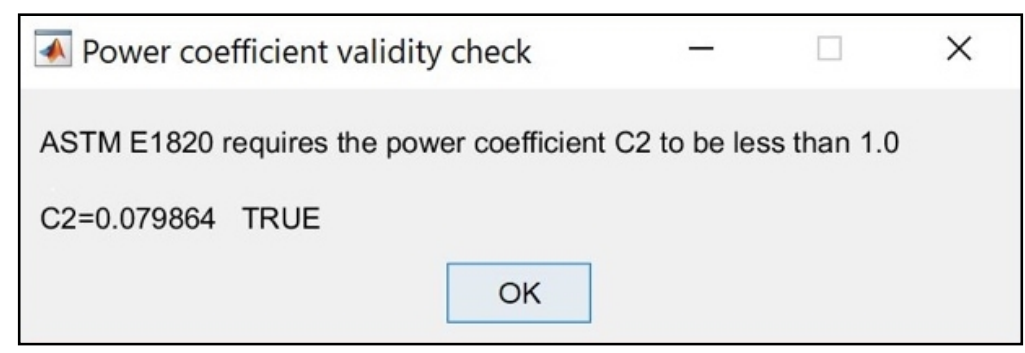

Fig. 11 Qualification of the fitting coefficient $C_{2}$. 


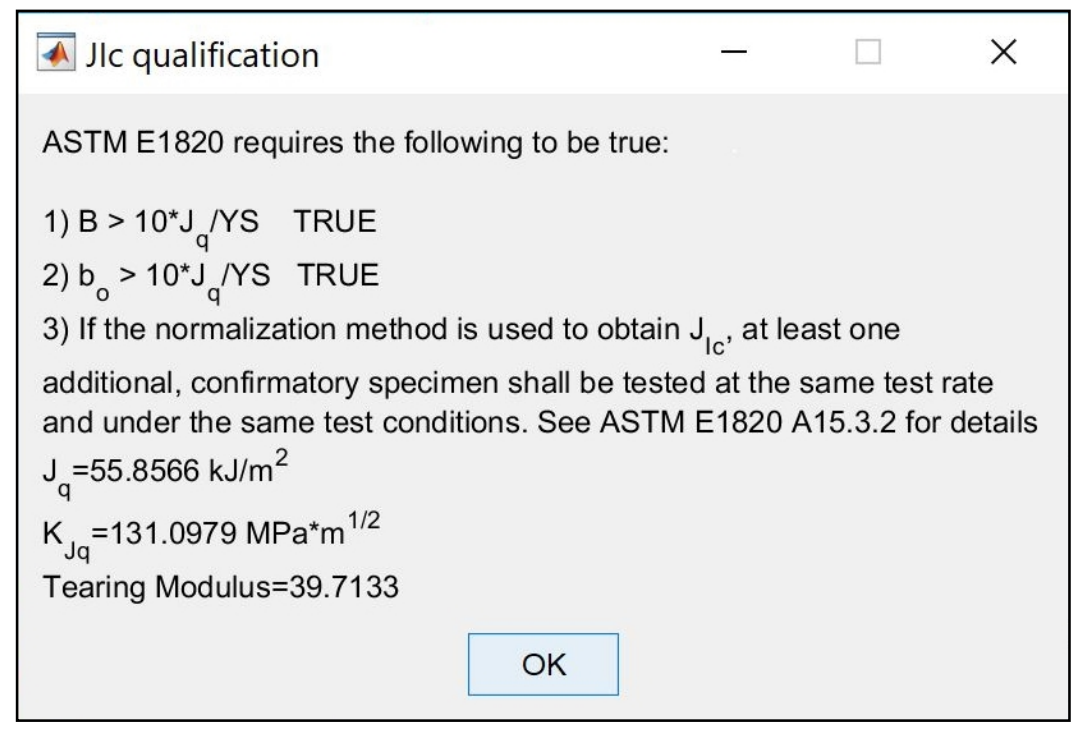

Fig. $12 \mathrm{~J}_{\mathrm{Ic}}$ qualification.

\subsection{Results Output}

Lastly, if the normalization analysis is successfully completed by the program, a final pop-up window (Fig. 12) will appear to let the user know that results have been saved in four text files and one png picture file. All output files have the specimen ID defined in section 3.3 as part of the file name extension, namely:

\begin{tabular}{ll}
\hline \multicolumn{1}{c}{ Output file name } & \multicolumn{1}{c}{ Output data type } \\
\hline \multirow{2}{*}{ AdjustedCrackLength-SpecimenID.txt } & $\begin{array}{l}\text { Adjusted crack length values per ASTM E1820 section } \\
\text { A15.2.8 }\end{array}$ \\
\hline JRresults-SpecimenID.txt & J-R curve data, $\mathrm{J}_{\mathrm{q}}, \mathrm{K}_{\mathrm{Jq}}$, and tearing modulus results \\
\hline FittingParameters-SpecimenID.txt & $\begin{array}{l}\text { Fitting parameters in the normalization analysis (see Eq. } \\
\text { A15.5 in ASTM E1820) }\end{array}$ \\
\hline InputInitialParameters-SpecimenID.txt & Material/test parameters defined in section 3.4 \\
\hline JRcurve-SpecimenID.png & The J-R curve picture \\
\hline
\end{tabular}

\section{Analysis complete}

Data are stored as:

FittingParameters-TEST-1.txt

AdjustedCrackLength-TEST-1.txt

JRresults-TEST-1.txt

InputInitialParameters-TEST-1.txt

JRcurve-TEST-1.png

\section{OK}

Fig. 13 Pop-up window for output files. 


\section{APPENDICES}

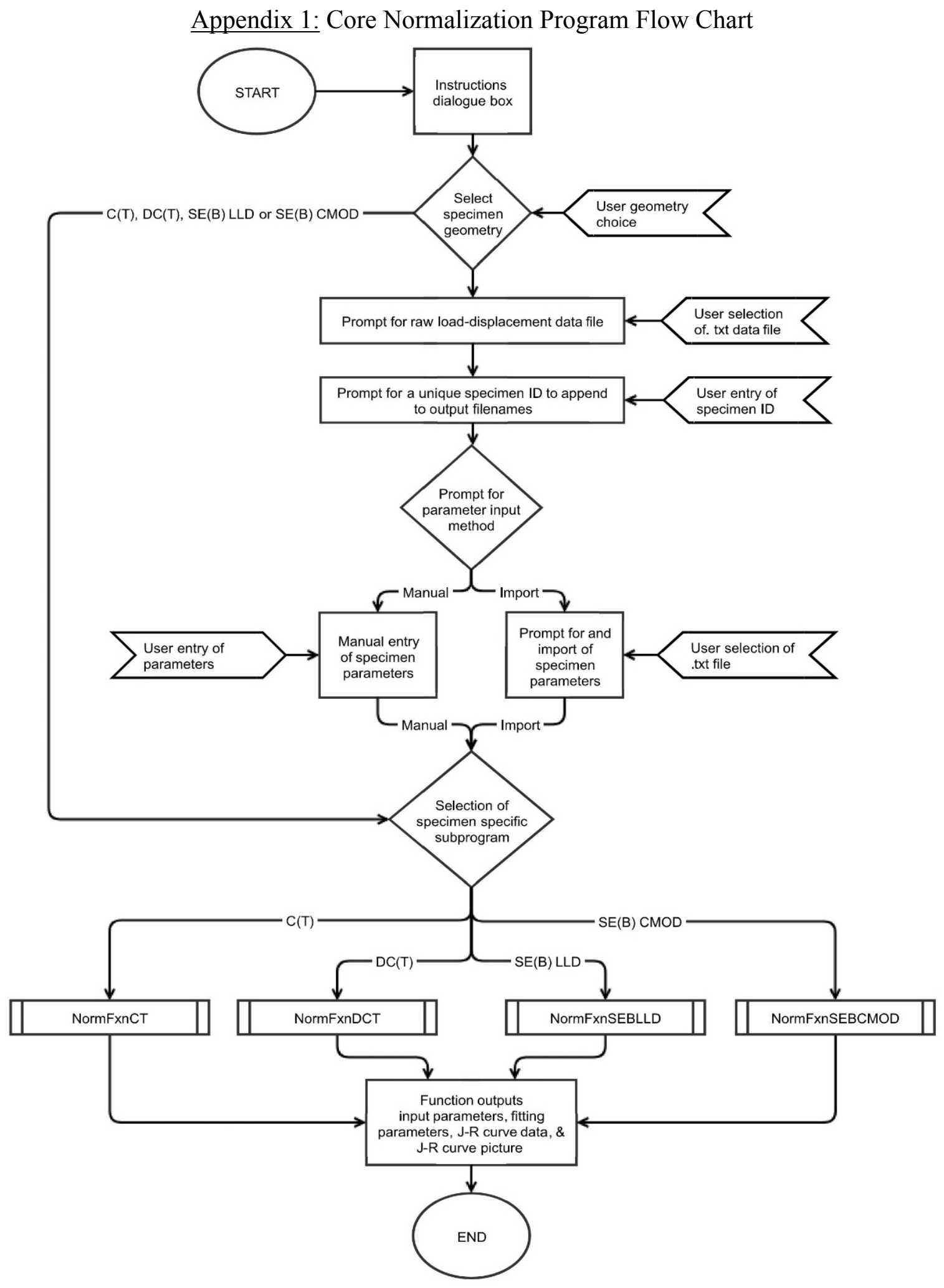




\section{Appendix 2: Normalization Function Program Flow Chart}

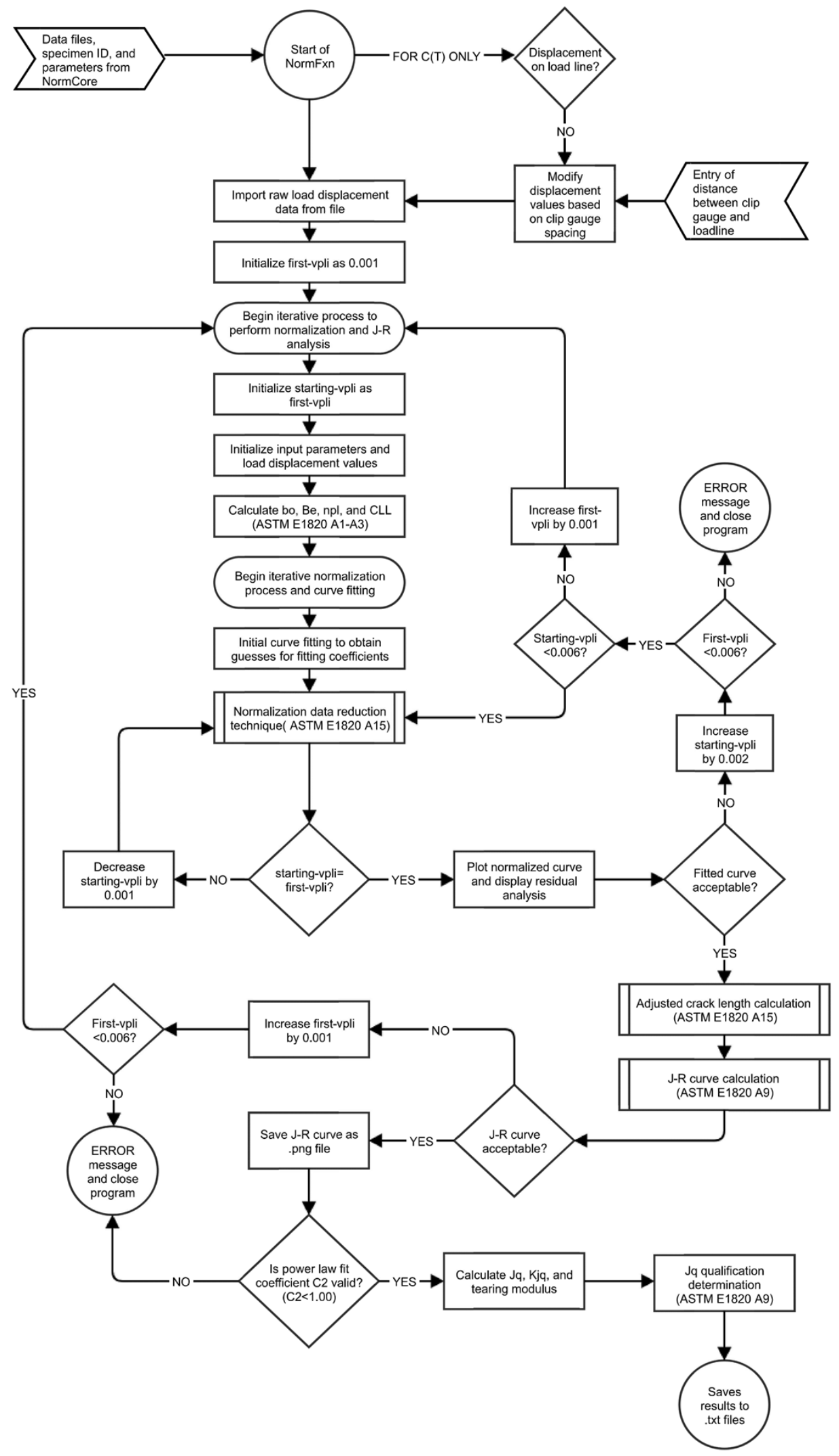




\section{REFERENCES}

[1] ASTM E1820-18: Standard Test Method for Measurement of Fracture Toughness, ASTM International, West Conshohocken, PA, 2018.

[2] J.D. Landes, J Calculation from Front Face Displacement Measurement on a Compact Specimen, International Journal of Fracture, 16 (1980) 183-186.

[3] P.C. Paris, H. Tada, A. Zahoor, and H. Ernst, The Theory of Instability of the Tearing Mode of Elastic-Plastic Crack Growth, ASTM STP 668 (1979) 5-36. 